\title{
Coronary stenting before coronary artery bypass graft surgery in diabetic patients does not increase the perioperative risk of surgery
}

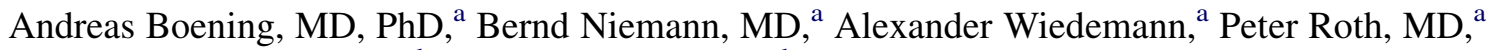 \\ Rolf-Hasso Bödeker, $\mathrm{PhD},{ }^{\mathrm{b}}$ Christine Scheibelhut, ${ }^{\mathrm{b}}$ and Markus Schönburg, $\mathrm{MD}, \mathrm{PhD}^{\mathrm{c}}$
}

\begin{abstract}
Objective: A negative relationship between coronary stenting before coronary artery bypass graft (CABG) surgery and the perioperative mortality and morbidity has been shown in diabetic patients. We tried to assess this relationship in a 2-institution database.
\end{abstract}

\begin{abstract}
Methods: In the years 2005 and 2006, 1125 of 3311 patients undergoing CABG surgery had diabetes mellitus $(33.9 \%)$, and $185(16.4 \%)$ of the diabetic patients had at least 1 previous stent. There was no evidence of any clinically significant difference in the preoperative and intraoperative parameters between diabetics with or without previous stents.

Results: Thirty-day mortality (no-stent group, $3.86 \%$; stent group, $1.62 \%$ ) and postoperative major adverse cardiovascular and cerebrovascular events (MACCEs; mortality, stroke, myocardial infarction, renal failure) (nostent group, $12.2 \%$; stent group, $5.9 \%$ ) occurred more often in diabetic patients without coronary stents. Logistic regression for 30-day mortality using possible confounders including preoperative stent showed a significant positive effect of preoperative coronary stenting (OR, 0.157; 95\% CI limits, 0.033-0.737). Taking percutaneous coronary intervention out of the calculation model, this positive effect was no longer significant (OR, 0.344; CI, 0.091-1.298). Logistic regression for perioperative MACCE, with as well as without percutaneous coronary intervention as a confounder, also showed a significant positive effect of preoperative coronary stenting (OR, 0.231; 95\% CI, 0.091-0.590).
\end{abstract}

Conclusions: Coronary stenting before CAGB in diabetic patients does not predispose to a higher perioperative risk regarding mortality and morbidity after CABG surgery. (J Thorac Cardiovasc Surg 2011;142:e53-7)

\begin{abstract}
A negative relationship between coronary stenting before coronary artery bypass grafting $(\mathrm{CABG})$ surgery and the perioperative mortality and morbidity has been shown by Thielmann and associates for multiple coronary stenting in diabetic patients, ${ }^{1}$ as well as in patients without diabetes. ${ }^{2}$ This could be reproduced by other authors. ${ }^{3,4}$ Although these manuscripts showed a worse outcome after cardiac surgery in patients who were underwent stenting before CABG compared with those not receiving stents, the causal relationship remained unclear. Authors showing a higher perioperative mortality in patients with a previous stent before CABG could only speculate about reasons for the worse surgical outcome in previously stented patients:
\end{abstract}

- Coronary endothelial injury with intimal hyperplasia owing to repeat stent lesions ${ }^{5,6}$

\footnotetext{
From the Departments of Cardiovascular Surgery ${ }^{\mathrm{a}}$ and Medical Statistics, ${ }^{\mathrm{b}}$ University of Giessen; and the Department of Cardiovascular Surgery, ${ }^{c}$ Kerckhoff Clinic, Bad Nauheim, Germany.

Disclosures: Authors have nothing to disclose with regard to commercial support.

Received for publication July 30, 2010; revisions received Nov 9, 2010; accepted for publication April 15, 2011.

Address for reprints: Andreas Boening, MD, PhD, Department of Cardiovascular Surgery, University Hospital Giessen, Rudolf-Buchheim-Straasse 7, 35392 Giessen, Germany (E-mail: andreas.boening@chiru.med.uni-giessen.de).

$0022-5223 / \$ 36.00$

Copyright (C) 2011 by The American Association for Thoracic Surgery

doi:10.1016/j.jtcvs.2011.04.018
}

- Microvascular thrombotic obstruction and/or distal microembolization owing to platelet microaggregates ${ }^{7,8}$

- Compromised collateral blood flow by multiple contiguous and overlapping stents ${ }^{9}$

- Surgical coronary anastomoses have to be done on peripheral vessel regions where the target vessels are smaller in diameter, possibly leading to a compromised runoff and/or impaired patency rate ${ }^{2}$

- Preexisting stent-induced myocardial damage, side branch occlusion after stent ${ }^{3}$

- Perioperative stent thrombosis ${ }^{3}$

- Multiple small infarctions during/after percutaneous coronary intervention (PCI) shown by troponin I release ${ }^{10}$ leading to left ventricular mass loss by irreversible myocardial injury ${ }^{11}$

Using a 2-institutional database, we tried to assess the negative relationship between preoperative coronary stenting and postoperative results after CABG surgery. The parameters of choice were (1) 30-day survival and (2) the rate of perioperative major adverse cardiovascular and cerebrovascular events (MACCEs) (mortality, cerebrovascular infarctions, myocardial infarctions, and renal failure).

\section{METHODS}

\section{Study Population}

In an attempt to reproduce the negative influence of stenting before $\mathrm{CABG}$, we analyzed retrospectively the surgical database of 2 institutions. 


\section{Abbreviations and Acronyms \\ $\mathrm{CABG}=$ coronary artery bypass grafting \\ $\mathrm{CI} \quad=$ confidence interval \\ $\mathrm{ECC}=$ extracorporeal circulation \\ $\mathrm{IABP}=$ intra-aortic balloon pump \\ MACCE $=$ major adverse cardiovascular and cerebrovascular event \\ $\mathrm{OR} \quad=$ odds ratio \\ PCI = percutaneous coronary intervention}

We used the German Health Quality System (BQS Institute for Quality and Patient Safety) as a base for our data evaluation and added several items of interest, gaining 209 items in total. Altogether, there was information about 3311 patients undergoing isolated CABG in the years 2005 and 2006 in our 2 institutions.

Of the 3311 patients, $1125(34.0 \%)$ had diabetes mellitus. The diabetic patients were not classified according to the kind of diabetes or according to the duration of their diabetic state, but only according to their actual treatment: no treatment ( $0 \%$ of the stent group, $0.5 \%$ of the no-stent group), diet only ( $10.8 \%$ of the stent group, $13.7 \%$ of the no-stent group), oral medication ( $47.6 \%$ of the stent group, $44.7 \%$ of the no-stent group), insulin therapy ( $41.6 \%$ of the stent group, $41.1 \%$ of the no-stent group).

Owing to missing data concerning the dependent and independent variables of interest, only 1092 of the 1125 patients went into the final analysis, and $185(16.9 \%)$ of these 1092 diabetic patients were stented. The median time between last stenting and surgery was 82.5 days $(n=42$, range $0-3186$ days). The majority of stents $(113 ; 71.5 \%)$ were bare-metal stents, whereas only $16(16.5 \%)$ were drug-eluting stents. Nineteen $(12.0 \%)$ patients had a combination of both.

The numbers of interventions with stent implantation were as follows: only 1 PCI ( $72.6 \%$ of the stent group), 2 PCIs ( $20.6 \%$ of the stent group), 3 PCIs (5.5\% of the stent group), and more than 4 PCIs (1.4\% of the stent group).

Indications for CABG surgery were de novo stenoses in $40.9 \%(n=72)$ and in-stent restenoses - either alone or combined with de novo stenosesin $59.1 \%(\mathrm{n}=104)$. Because of the high patient numbers, even small, and possibly clinically irrelevant, differences reach statistical significance.

\section{Definitions}

Thirty-day mortality included all deaths within this time frame. MAC$C E s$ were new-onset myocardial infarction, dialysis, stroke, or 30-day mortality. Stroke was a persistent or transitory neurologic event. Myocardial infarction was defined as maximum creatine kinase MB elevation 3 times above the upper normal level and new $\mathrm{Q}$ waves in the electrocardiogram or the proof of new wall motion disturbances in the echocardiogram. Complete revascularization was defined as all planned anastomoses done.

\section{Perioperative Management}

Myocardial revascularization was performed in all patients via median sternotomy and a heparin dose suited to keep activated coagulation time greater than 400 seconds. Protamine was administered to antagonize heparin in a 1:1 dose. All patients received aspirin after surgery (beginning orally on day 1); clopidogrel was given only in patients with stents having an indication for this drug.

In both groups, the majority of the patients $(\mathrm{n}=988,97.9 \%$ no-stent group; $\mathrm{n}=181,97.8 \%$ previous stent group) were operated on using extracorporeal circulation (ECC) with mild hypothermia $\left(32^{\circ} \mathrm{C}-34^{\circ} \mathrm{C}\right)$, ascending aortic and venous 2-stage cannulation, as well as Bretschneider cardioplegia $(n=196 ; 21.6 \%$ no-stent group, $n=41 ; 22.2 \%$ previous- stent group), or blood cardioplegia ( $\mathrm{n}=678 ; 74.8 \%$ no-stent group, $\mathrm{n}=138 ; 74.6$ previous-stent group). There was a high percentage of internal thoracic artery use $(n=873 ; 96.4 \%$ no-stent group, $n=164 ; 88.7 \%$ previous-stent group). Bilateral internal thoracic artery use $(\mathrm{n}=121$; $13.4 \%$ no-stent group, $\mathrm{n}=22 ; 11.9 \%$ previous-stent group) and radial artery use $(\mathrm{n}=170 ; 18.8 \%$ no-stent group, $\mathrm{n}=41 ; 22.2 \%$ previous-stent group) was more frequent than reported for German heart centers. ${ }^{12}$

The number of grafts was as follows: 1 bypass graft $(3.2 \%$ of the stent group, $1.7 \%$ of the no-stent group), 2 bypass grafts $(32.4 \%$ of the stent group, $22.7 \%$ of the no-stent group), 3 bypass grafts $(52.9 \%$ of the stent group, $61.4 \%$ of the no-stent group), 4 bypass grafts $(10.3 \%$ of the stent group, $12.4 \%$ of the no-stent group), 5 bypass grafts $(0.5 \%$ of the stent group, $1.5 \%$ of the no-stent group), and 6 bypass grafts $(0.5 \%$ of the stent group, $0.1 \%$ of the no-stent group).

\section{Statistical Analysis}

A descriptive statistical analysis comparing diabetic patients in the stented and nonstented groups was carried out using the SAS statistical system version 9.2 (SAS Institute, Inc, Cary, NC). Fisher's exact test was used to test differences between patients with or without a stent in case of nominal or ordinal scaled variables. The Hodges-Lehmann estimator was calculated to determine differences between population medians. Inasmuch as the continuous variables of interest were not normally distributed, the Wilcoxon-Mann-Whitney test was used to test possible differences between the location of the distribution in both groups. To prove homogeneity concerning the possible confounders, we computed the Mann-Whitney estimator (associated effect size measure for the Wilcoxon-Mann-Whitney test) and the corresponding $90 \%$ confidence interval (CI).

In a first step, the influence of the possible confounders (preoperative data: intra-aortic balloon pumping [IABP], preoperative PCI, EuroSCORE; intraoperative data: complete revascularization, ECC time) on 30-day mortality or MACCE, respectively, was evaluated. Because preoperative factors like age, gender, and left ventricular function were included in the EuroSCORE, these factors were not analyzed separately. In a second step, the associations between the possible confounders were evaluated. Taking these results into account from the clinical point of view, a model for logistic regression to investigate the influence of preoperative stenting on 30-day mortality or occurrence of MACCE, respectively, was defined.

Both analyses included IABP, PCI, and EuroSCORE before surgery, intraoperative ECC time, and complete revascularization as confounders. These analyses were done in an exploratory sense; therefore, all computed $P$ values will be given.

\section{RESULTS}

Testing homogeneity, small-sized group differences in the preoperative and intraoperative parameters between patients with coronary stents (stent group) and patients without coronary stents (no-stent group) could be observed for only 3 parameters using the Mann-Whitney estimator for group differences: patients in the stent group were younger (68 vs 70 years) and had more reoperations ( 13.0 vs $3.3 \%$ ), as well as fewer neurologic diseases (3.8 vs $8.8 \%$ ) (Table 1$)$.

Although procedure time was similar in both groups during surgery, ECC time and aortic clamping time were longer in the no-stent group (Table 2).

The rates of 30-day mortality (no-stent group, $3.86 \%$; stent group, $1.62 \% ; P$ Fisher's exact $=.184$ ) and MACCEs (no-stent group, $10.0 \%$, stent group, $\left.4.3 \%, P_{\text {Fisher's exact }}=.012\right)$ were higher in the no-stent group (Table 3). In accordance with these univariate results, the multivariate analyses could 
TABLE 1. Demographic data of diabetic patients before surgery

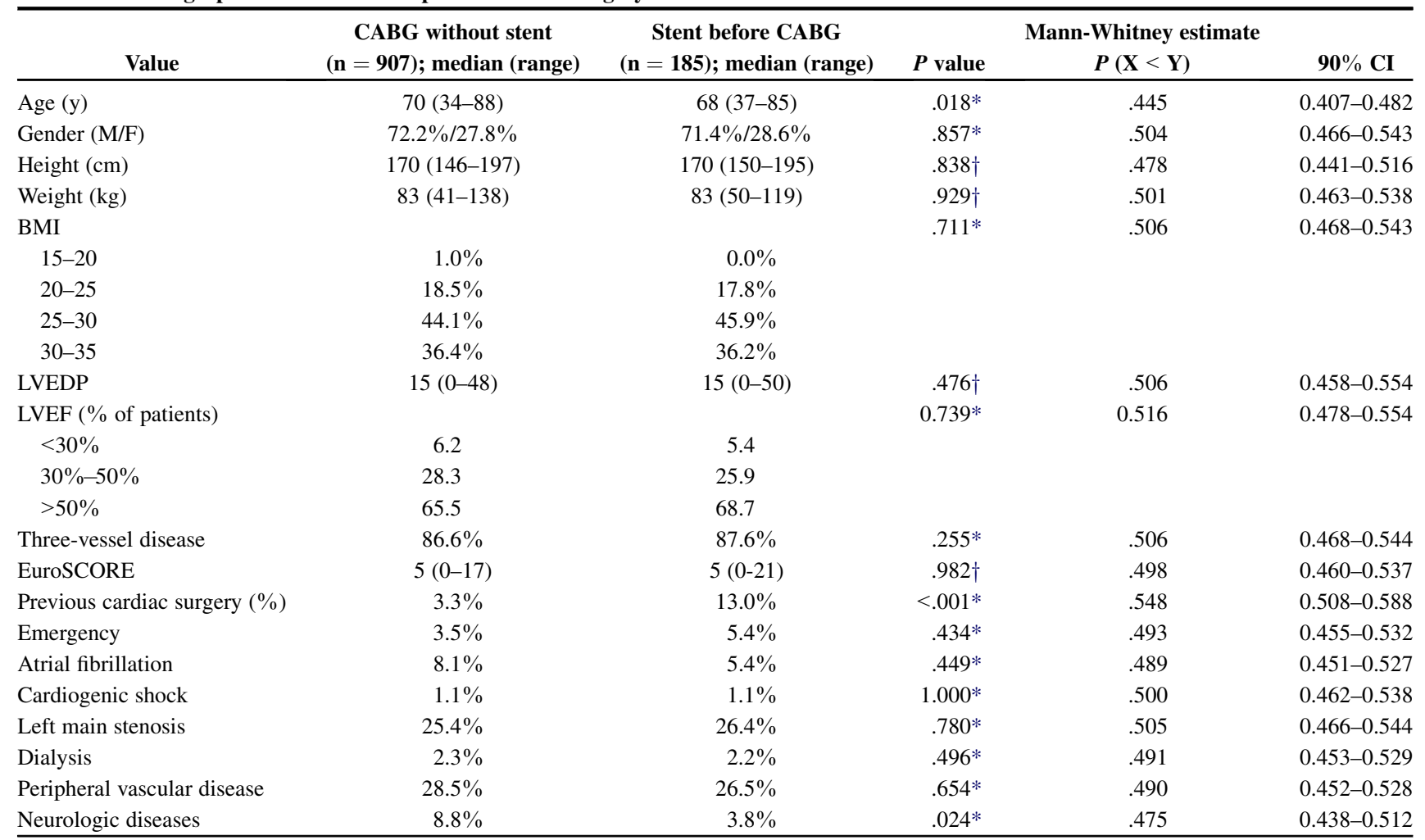

$C A B G$, Coronary artery bypass graft; $C I$, confidence interval; $M / F$, male/female; $B M I$, body mass index; $L V E F P$, left ventricular end-diastolic pressure; $L V E F$, left ventricular ejection fraction. *Fisher's exact test. $\dagger$ Median test.

show a connection between preoperative stenting and the results of CABG (Tables 4 and 5) when the parameters EuroSCORE, intraoperative IABP insertion, complete revascularization, ECC time, und preoperative PCI were included in the analysis as possible confounders. Especially for the dependent variable 30-day mortality, the possible influence of the independent variable stenting depends on the set of confounders in the model. With the 5 confounders mentioned above, patients with stenting before surgery had a significantly $(P=.019$; odds ratio [OR], 0.157 ; $95 \%$ CI, 0.03-0.74) lower mortality risk. Leaving out the confounder PCI, the mortality risk was not significantly different anymore $(P=.115$; OR, $0.344 ; 95 \%$ CI, 0.09-1.29). That means that, depending on the calculation model, in our patient group the risk of dying early after CABG surgery for diabetic patients with stenting before surgery was either lower than or equal to, but not higher than, that for nonstented diabetic patients. We could not find evidence supporting former reports of a higher perioperative death risk for patients with coronary stenting before CABG surgery.

For the perioperative MACCE rate, the same applies, but the influence of stenting on the MACCE rate is less dependent on the set of confounders in the model.

We found a significantly higher cerebrovascular event rate in the no-stent group (no-stent group, $4.41 \%$; stent group, $\left.1.08 \% ; P_{\text {Fisher's exact }}=.034\right)$. Postoperative median length of stay in the hospital (8 days in both groups) was not significantly different between the groups.

\section{DISCUSSION}

This retrospective study $(n=1092)$ cannot confirm previously published reports stating that multiple previous stenting is associated with a high mortality after CABG

TABLE 2. Intraoperative data

\begin{tabular}{|c|c|c|c|c|c|}
\hline \multirow[b]{2}{*}{ Value } & \multirow{2}{*}{$\begin{array}{c}\text { CABG without stent } \\
(\mathbf{n}=907) ; \text { median (range) }\end{array}$} & \multirow{2}{*}{$\begin{array}{c}\text { Stent before CABG } \\
(\mathrm{n}=185) ; \text { median (range) }\end{array}$} & \multicolumn{3}{|c|}{ Mann-Whitney estimate } \\
\hline & & & $\boldsymbol{P}$ & $\boldsymbol{P}(\mathbf{X}<\mathbf{Y})$ & $90 \% \mathrm{CI}$ \\
\hline Procedure time $(\mathrm{min})$ & $215(99-476)$ & $215(110-606)$ & $.977 *$ & .487 & $0.450-0.523$ \\
\hline ECC time (min) & $103(0-260)$ & $100(0-230)$ & $.077 *$ & .455 & $0.417-.0492$ \\
\hline Aortic clamping time (min) & $63(0-195)$ & $60(0-157)$ & $.054^{*}$ & .458 & $0.421-0.495$ \\
\hline Complete revascularization & $89.1 \%$ & $89.7 \%$ & $.897 \dagger$ & .503 & $0.465-0.541$ \\
\hline
\end{tabular}

Complete revascularization

$89.1 \%$

$89.7 \%$

$.897 \dagger$ 
TABLE 3. Postoperative data

\begin{tabular}{lccc}
\hline \multicolumn{1}{c}{ Value } & $\begin{array}{c}\text { CABG } \\
\text { without stent } \\
(\mathbf{n = 9 0 7 ) ;} \%\end{array}$ & $\begin{array}{c}\text { Stent before } \\
\text { CABG } \\
(\mathbf{n}=\mathbf{1 8 5}) ; \%\end{array}$ & $\begin{array}{c}\boldsymbol{P} \text { (Fisher's } \\
\text { exact test) }\end{array}$ \\
\hline Thirty-day mortality & 3.86 & 1.62 & .184 \\
MACCE & 10.0 & 4.3 & .012 \\
Myocardial infarction & 1.10 & 0.54 & .701 \\
Rethoracotomy & 5.40 & 4.32 & .716 \\
Cerebrovascular event & 4.41 & 1.08 & .034 \\
Dialysis & 2.87 & 2.70 & 1.000 \\
Blood transfusion & 41.28 & 46.49 & .192 \\
Infection & 10.69 & 6.49 & .105 \\
Atrial fibrillation & 29.3 & 27.6 & .658 \\
\hline CABG, Coronary artery bypass graft; $M A C C E$, major adverse cardiovascular and ce- \\
rebrovascular event.
\end{tabular}

surgery. ${ }^{1-4}$ This association has also been described for diabetic patients, in whom not multiple, but single stenting has been shown as a risk factor. ${ }^{1}$ In our data set, we found no evidence that single or multiple stenting before surgery increases the surgical risk in patients with coronary artery disease who have diabetes. In the previously published reports ${ }^{1-4}$ with meticulously used and elaborate statistical methods, no evidence was given about the causality and the pathomechanisms of a higher surgical mortality in previously stented patients.

Checking the homogeneity of the 2 groups regarding demographic data before surgery, we found that small intergroup differences could be observed in only 3 of the 17 variables (age, previous cardiac surgery, and neurologic diseases) using the Mann-Whitney estimator for group differences (Table 1). Similarly, small differences between the 2 groups were seen regarding the intraoperative data: ECC time and aortic clamping time (Table 2). Why should a difference of 3 minutes (Hodges-Lehmann estimator for aortic clamping time, Table 2) or of 5 minutes (Hodges-Lehmann estimator for ECC time medians) cause a remarkable clinical difference between the 2 investigated groups?

The main end points of our study, 30-day mortality and MACCE rate, are different between patients having a stent before surgery or not. However, in contrast to the mentioned

TABLE 4. Logistic regression for the response variable survival in 1092 diabetic CABG patients (with and without confounder stent)

\begin{tabular}{|c|c|c|c|}
\hline Variable & $P$ value & OR & CI \\
\hline $\begin{array}{l}\text { Stenting before surgery } \\
\text { (with confounders: } P C I \text {, EuroSCORE, } \\
\text { IABP, complete revascularization, } \\
\text { ECC time) }\end{array}$ & .019 & 0.157 & $0.033-0.738$ \\
\hline $\begin{array}{l}\text { Stenting before surgery (with } \\
\text { confounders: EuroSCORE, IABP, } \\
\text { complete revascularization, } \\
\text { ECC time) }\end{array}$ & .115 & 0.344 & $0.091-1.298$ \\
\hline
\end{tabular}

TABLE 5. Logistic regression for the response variable $M A C C E$ in 1092 diabetic CABG patients (with and without confounder PCI)

\begin{tabular}{lccc}
\hline \multicolumn{1}{c}{ Variable } & $\boldsymbol{P}$ value & OR & $\mathbf{9 5} \%$ CI \\
\hline Stenting before surgery (confounders: & .002 & 0.232 & $0.091-0.593$ \\
$\quad \begin{array}{l}P C I, \text { EuroSCORE, IABP, complete } \\
\text { revascularization, ECC time) }\end{array}$ & & & \\
$\begin{array}{l}\text { Stenting before surgery (confounders: } \\
\quad \begin{array}{l}\text { EuroSCORE, IABP, complete } \\
\text { revascularization, ECC time) }\end{array}\end{array}$ & .0151 & 0.383 & $0.176-0.830$ \\
\hline
\end{tabular}

$M A C C E$, Major adverse cardiovascular and cerebrovascular event; $C A B G$, coronary artery bypass graft; $P C I$, percutaneous coronary intervention; $O R$, odds ratio; $C I$, confidence interval; $I A B P$, intra-aortic balloon pump; $E C C$, extracorporeal circulation.

previous studies, these differences were in favor of stenting before surgery! Depending on inclusion of the confounder PCI into the analysis, in the multivariate (Table 5) logistic regression, stenting before surgery was an influencing factor for our 2 study end points or not. Why patients with stents before surgery should have a better outcome after surgery is unclear; therefore, we are cautious about overinterpreting our data in that direction, especially in the light of our second finding that the differences between no-stent and stent patients vanish if we take the confounder PCI out of the calculation. One reason that stented patients fare better over the CABG surgery phase could be that they are usually treated with platelet inhibitors either dually or for a longer period of time without stopping this treatment before surgery.

We are well aware that our results are in direct contrast to previously published results of several authors: The most recent analysis of Massoudy and associates ${ }^{4}$ and the article by Thielmann and colleagues, ${ }^{2}$ show that patients with more than 2 coronary interventions before coronary surgery have a higher surgical risk than patients without or with only 1 coronary stent. However, these authors fail to describe convincingly the reasons for this higher surgical risk.

Differences to other publications are that we did not limit our analysis to elective patients ${ }^{2}$ but included every consecutive patient having isolated CABG surgery in this 2-year period into this analysis. We did avoid a case-control analysis over a long time period ${ }^{3}$ but chose a complete data set analysis of all consecutive patients having CABG surgery within a narrow 2-year time frame. Whereas Massoudy and associates ${ }^{4}$ described MACCEs and mortality only as in-hospital data, we produced 30-day data.

In contrast to the article of Bonaros and colleagues, ${ }^{3} \mathrm{pa}-$ tients of the stent group in our study did not experience more perioperative complications (new renal insufficiency, rethoracotomies, blood transfusions) than did patients in the no-stent group. This difference is explainable by a worse preoperative status regarding history of myocardial infarctions, left ventricular ejection fraction, and the use of platelet antiaggregation agents of the stent patients in Bonaros' study ${ }^{3}$ but not in our study. 
Long-term results are analyzed by Chocron and colleagues, ${ }^{13}$ who described a higher incidence of MACCEs in patients with previous stenting $(17.0 \%)$ than in patients without previous stenting $(11.6 \%)$ before CABG surgery. The time frame of this study based on the dataset of the IMAGINE trial was a follow-up time of 2.95 years. Nothing is mentioned regarding the short-term results of $\mathrm{CABG}$ after coronary stenting in this report.

\section{Limitations}

With our analysis, we can only state that in our patient cohort there is a possible relationship between coronary stenting and the results of subsequent coronary surgery, but in a completely different way from those described in previous articles. The causality of this relationship is unclear so far.

Although a causal relationship between previous coronary stent and worse results after CABG surgery has not been proven, and our results speak against this hypothesis, more trials-prospective and/or randomized-have to be done. This causal relationship could possibly be explained from a prospective randomized trial, ${ }^{14}$ where the mortality of first interventionally but then surgically treated coronary patients could be compared with the results of first surgically treated patients.

Although in our group of patients we could not show that coronary stenting before CAGB predisposes to a higher perioperative risk regarding mortality and morbidity after CABG surgery, caution is warranted: the current practice of stenting a coronary artery first and sending the patient to surgery if stenting fails has to be questioned.

\section{CONCLUSIONS}

In our group of diabetic patients, coronary stenting before CAGB does not increase the perioperative risk regarding mortality and morbidity of CABG surgery. In the light of contradictory results of other studies, the current practice of stenting a coronary artery first and sending the patient to surgery if stenting fails has to be questioned.

\section{References}

1. Thielmann M, Neuhäuser M, Knipp S, Kottenberg-Assenmacher E, Marr A, Pizanis N, et al. Prognostic impact of previous percutaneous coronary intervention in patients with diabetes mellitus and triple-vessel disease undergoing coronary artery bypass surgery. J Thorac Cardiovasc Surg. 2007;134:470-6.

2. Thielmann M, Leyh R, Masoudy P, Neuhäuser M, Aleksic I, Kamler M, et al. Prognostic significance of multiple previous percutaneous coronary interventions in patients undergoing elective coronary artery bypass surgery. Circulation. 2006;114(Suppl I):I441-7.

3. Bonaros N, Hennerbichler D, Friedrich G, Kocher A, Pachinger O, Laufer G, et al. Increased mortality and perioperative complications in patients with previous elective percutaneous coronary interventions undergoing coronary artery bypass surgery. J Thorac Cardiovasc Surg. 2009;137:846-52.

4. Massoudy P, Thielmann M, Lehmann N, Marr A, Kleikamp G, Maleszka A, et al. Impact of prior percutaneous coronary intervention on the outcome of coronary artery bypass surgery: a multicenter analysis. J Thorac Cardiovasc Surg. 2009; 137:840-5.

5. Tsagalou E, Chieffo A, Iakovou I, Ge L, Sangiorgi GM, Corvaja N, et al. Multiple overlapping drug-eluting stents to treat diffuse disease of the left anterior descending coronary artery. J Am Coll Cardiol. 2005;45:1570-3.

6. Hofma SH, van der Giessen WJ, van Dalen BM, Lemos PA, McFadden EP, Sianos G, et al. Indication of long-term endothelial dysfunction after sirolimus-eluting stent implantation. Eur Heart J. 2006;27:166-70.

7. Herrmann J. Peri-procedural myocardial injury: 2005 update. Eur Heart J. 2005; 26:2493-519.

8. Toutouzas K, Colombo A, Stefanidis C. Inflammation and restenosis after percutaneous coronary interventions. Eur Heart J. 2004;25:1679-87.

9. Alfonso F, Hernandez C, Perpez-Vizcayno MJ, Hernandez R, FernandezOrtiz A, Escaned J, et al. Fate of stent-related side branches after coronary intervention in patients with in-stent restenosis. J Am Coll Cardiol. 2000;36:1549-56.

10. Cantor WJ, Newby K, Christenson RH, Tuttle RH, Hasselblad V, Armstrong PW, et al. Prognostic significance of elevated troponin I after percutaneous coronary intervention. J Am Coll Cardiol. 2002;39:1738-44.

11. Selvanayagam JB, Porto I, Channon K, Petersen SE, Francio JM, Neubauer S Troponin elevation after percutaneous coronary intervention directly represents the extent of irreversible myocardial injury: insights from cardiovascular magnetic imaging. Circulation. 2005;111:1027-32.

12. Gummert JF, Funkat A, Beckmann A, Schiller W, Hekmat K, Ernst M, et al. Cardiac surgery in Germany during 2007. Thorac Cardiovasc Surg. 2008;56:328-36.

13. Chocron S, Baillot R, Rouleau JL, Warnica WJ, Block P, Johnstone D, et al. Impact of previous percutaneous transluminal coronary angioplasty and/or stenting revascularization on outcomes after surgical revascularization: insights from the IMAGINE study. Eur Heart J. 2008;29:673-9.

14. Serruys PW, Morice MC, Kappetein AP, Colombo A, Holmes DR, Mack MJ et al., SYNTAX Investigators. Percutaneous coronary intervention versus coronary-artery bypass grafting for severe coronary artery disease. $N$ Engl J Med. 2009;360:961-72. 